\title{
The meaning of the Bulgarian evidential and why it cannot express inferences about the future*
}

\author{
Anastasia Smirnova \\ The Ohio State University and Tufts University
}

\begin{abstract}
The paper presents a uniform analysis of the Bulgarian evidential in reportative and inferential contexts. The Bulgarian evidential is analyzed as having both a temporal and an epistemic modal component. The analysis allows one to explain why the evidential can be used to report false beliefs in reportative contexts but not in inferential ones, as well as why the Bulgarian evidential cannot express inferences about the future. Both cases are problematic for the previous analyses of evidentiality in Bulgarian (Izvorski 1997, Koev 2011).
\end{abstract}

Keywords: Evidentiality, tense, modality, Bulgarian

\section{Background on evidentiality in Bulgarian}

Evidentiality is a category that expresses the source of information on which the statement is based. Most commonly, languages encode the difference between direct observation, report and inference (cf. Willett 1988, Aikhenvald 2004). Bulgarian has a designated verbal paradigm that expresses evidential meaning (discussed in section 2). A single verb form in the evidential paradigm can express either reportative or inferential evidence, depending on the context (cf. Izvorski 1997). For example, in (1) the evidential form pisala 'write' expresses that the speaker's source of information for her claim that Maria was writing a book is a report. The same form in (2) expresses that the speaker's source of information is inference. The type of evidential meaning is specified in square brackets. ${ }^{1}$

\footnotetext{
* This paper is a continuation of my dissertation research. I thank Brian Joseph, Judith Tonhauser and Craige Roberts for their detailed feedback and Anastasia Giannakidou, Stefan Kaufmann, Yusuke Kubota, Roumyana Pancheva, Magdalena Schwager, and the participants of SALT 21 for useful discussions. I'm grateful to Jungmee Lee and to the editors of this volume for their comments on an earlier draft of this paper. The usual disclaimer applies.

1 Glosses and abbreviations: EV=Evidential operator, FUT=Future marker, IMPERF= Imperfective Aspect, NOT $=$ Negation; PAST $=$ Past tense, PAST $=$ Past stem participial form, PERF=Perfective aspect, PRES=Present tense, PRES $=$ Present stem participial form, $P L=P l u r a l$, $\mathrm{PLE}=$ Participle, $\mathrm{REFL}=$ Reflexive marker, $\mathrm{SG}=$ Singular, $\mathrm{SUBJ}=$ Subjunctive marker.
} 
(1) Reportative context: Last week Ivan told you that Maria, your former classmate, spent last year writing a book, and that the book has just been published. You believe Ivan. At the class reunion, when someone asks you what Maria was doing last year, you say: ${ }^{2}$

Maria pisala kniga.

Maria write.IMPERF.PAST.PLE book

'Maria was writing a book, [I heard].'

(2) Inferential context: Your late aunt Maria spent two months before her death in Paris. After her funeral, you found an unfinished manuscript about Paris in her apartment. You inferred that shortly before her death Maria was writing a book. When one of the relatives wonders what Maria was doing in Paris before she died, you say:

Maria pisala kniga.

Maria write.IMPERF.PAST.PLE book

'Maria was writing a book, [I inferred].'

In her influential paper, Izvorski (1997) proposes a uniform analysis of the Bulgarian evidential in inferential and reportative contexts. Her analysis is summarized in (3), where EV is the evidential operator and $p$ is the proposition in its scope:

(3) The interpretation of EV $p$ (Izvorski 1997: 226)

a. Assertion: $\square \mathrm{p}$ in view of the speaker's knowledge state.

b. Presupposition: Speaker has indirect evidence for $\mathrm{p}$.

Izvorski's analysis in (3) explains why the evidential form pisala 'write' is felicitous in (1) and (2): in both contexts the speaker is committed to the truth of the proposition $p(3 \mathrm{a})$, and the speaker has indirect evidence for $p(3 \mathrm{~b})$.

Given that in Bulgarian the same form can express inferential and reportative evidence, a uniform analysis of the evidential operator is highly desirable. However, below I show that there are differences between inferential and reportative contexts as far as the distribution of evidential forms is concerned. These cases present a potential problem for a uniform semantic analysis.

The first difference pertains to the speaker's epistemic commitment in reportative and inferential contexts. In reportative contexts, such as (4), the evidential can be used even if the speaker believes that the proposition $p$ in the scope of the evidential is false.

2 Evidential forms in Bulgarian bear participial morphology. I gloss them as participles (PLE) rather than evidentials (EV). 
The meaning of the Bulgarian evidential

(4) Reportative context: You just came from a psychiatric clinic, where you visited your friend Eli. Eli was hospitalized because of severe hallucinations and other psychological problems. When your friend inquires about the things Eli told you, you say:

Izvănzemnite í predložili rabota v kosmičeska laboratorija.

Aliens her offer.PERF.PAST.PLE job in space laboratory

'Aliens offered her a job in a space lab, [I heard].'

It is clear from the context in (4) that the speaker does not believe that poor Eli was offered a job by aliens.

Unlike reportative contexts, in inferential contexts the evidential form is infelicitous if the speaker believes that $p$ is false, as shown in (5).

(5) Inferential context: A month ago Maria applied for a highly competitive position in a NASA laboratory. When Maria announced that she is quitting her current job, you inferred that she got a job offer from NASA. Later, you learned that Maria was not offered a job by NASA. When your friend asks you why Maria is quitting her job, you say:

\#NASA í predložili rabota.

NASA her offer.PERF.PAST.PLE job

'NASA offered her a job, [I inferred].'

Since in Izvorski's uniform analysis the speaker considers $p$ to be necessarily true (cf. (3a)), the analysis predicts the evidential to be infelicitous if the speaker does not believe $p$. This prediction is not borne out, as the example in (4) shows. Moreover, the uniform analysis cannot explain why the speaker has to be committed to the truth of $p$ in inferential contexts (5) but not in reportative contexts (4).

The second difference between inferential and reportative contexts pertains to the distribution of evidential forms that have future time reference. Bulgarian has a designated future evidential form to refer to future events. In (6), the future evidential form štjala da piše 'will write' appears in a reportative evidential context and refers to some future time at which the eventuality of book writing is supposed to take place.

(6) Reportative context: In the morning Ivan told you that Maria will spend the evening writing a portion of her book. When in the afternoon your friend asks you what Maria will do in the evening, you say:

Maria štjala da piše kniga.

Maria FUT.PLE SUBJ write.IMPERF.3SG.PRES book

'Maria will be writing a book, [I heard].' 
However, when the future evidential form appears in an inferential context about the future, the intended evidential meaning is blocked, as shown in (7).

(7) Inferential context: By looking at your roommate Maria's schedule this morning you inferred that she plans to spend the evening writing a portion of her book. In the afternoon, when your friend asks you what Maria will do in the evening, you say:

\# Maria štjala da piše kniga.
Maria FUT.PLE SUBJ write.IMPERF.3SG.PRES book
Intended: 'Maria will be writing a book, [I inferred].'

The inability of future evidential forms to express inferences about the future is a well attested phenomenon not only in Bulgarian but in all Balkan languages that grammatically express evidentiality (cf. Newmark et al. 1982 on Albanian, AksuKoç and Slobin 1986: 163 on Turkish, Friedman 2005: 27 on Macedonian). However, this phenomenon has not been explored in the formal semantic literature. Why future evidential forms are felicitous in reportative but not in inferential contexts cannot be easily explained by a uniform semantic analysis such as Izvorski 1997.

The data presented in (4) - (7) raise the question of whether a uniform analysis of the Bulgarian evidential is still possible. In what follows, I propose a formal analysis of the evidential in Bulgarian that explains the contrast between reportative and inferential evidential contexts shown in (4) - (7), and, at the same time, is uniform. The paper is structured as follows. Section 2 provides background on evidential morphology. Section 3 is the analysis. I show that the Bulgarian evidential has both an epistemic modal component and a temporal component. Section 4 explains why future evidential forms cannot express inferences about the future. Section 5 compares the current proposal to the previous analyses of evidentiality in Bulgarian (Izvorski 1997, Koev 2011) and shows that it fares better than its competitors on empirical and theoretical grounds. Section 6 concludes the paper.

\section{Background on evidential morphology}

Bulgarian has a designated verbal paradigm that expresses evidential meaning. Thus, for each verb form in the indicative paradigm, there is a corresponding verb form in the evidential paradigm. Table 1 lists evidential and indicative forms of the Bulgarian verb piša 'write' in the $3^{\text {rd }}$ person singular, feminine gender.

The forms of the indicative paradigm bear aspect, number, person, and tense inflections. The morphological hallmark of evidential forms is the participia lmorpheme $-l-$, which is realized on the verb in the present (piše-l-) and in the past 
The meaning of the Bulgarian evidential

\begin{tabular}{lll}
\hline \hline & Indicative paradigm & Evidential paradigm \\
\hline \hline Present & $\begin{array}{l}\text { piše- } \varnothing \\
\text { write.IMPERF-3SG.PRES }\end{array}$ & $\begin{array}{l}\text { piše-l-a } \\
\text { write.IMPERF.PRES-PLE-FEM }\end{array}$ \\
\hline \hline Past & pisa- $\varnothing$ & pisa-l- $a$ \\
& write.IMPERF-3SG.PAST & write.IMPERF.PAST-PLE-FEM \\
\hline \hline Future & $\check{s} t e ~ p i \check{e}$ - $\varnothing$ & štja-l-a $a d a \quad$ piše- $\varnothing$ \\
& FUT write.IMPERF-3SG.PRES & FUT-PLE-FEM SUBJ write.IMPERF-3SG.PRES \\
\hline \hline
\end{tabular}

Table 1 The evidential and the indicative paradigm in Bulgarian.

(pisa-l-) form, and on the future auxiliary in the future form (štja-l-). The evidential forms for the present and for the past have distinct stems, i.e. piše- and pisa-, respectively, which, as I argue later, encode temporal information and function as relative tenses (cf. Smirnova 2011). Each evidential form bears clearly identifiable aspectual morphology (imperfective in the case of pisa- and piše-). As I show in the analysis section, aspectual and temporal morphemes make truth conditional contributions to the meaning of evidential sentences.

\section{The analysis of the Bulgarian evidential construction}

I propose that the meaning of evidential sentences in Bulgarian is derived from the semantic contribution of (i) the evidential operator, (ii) grammatical aspect, and (iii) tense. I argue that the evidential operator has both a modal and a temporal component. In section 3.1, I discuss the modal meaning of the Bulgarian evidential operator. Section 3.2 focuses on the temporal component of the evidential construction. Section 3.3. spells out the formal analysis.

\subsection{The epistemic modal component of the evidential construction}

Izvorski (1997) convincingly shows that in inferential evidential contexts the Bulgarian evidential has a modal component. According to her analysis, (i) the proposition $p$ in the scope of the evidential is interpreted with respect to the belief worlds of the speaker, and (ii) the speaker considers $p$ to be an epistemic necessity (see (3a)). The example in (8) supports the modal analysis by showing that the speaker's belief worlds, and not the actual world, are relevant for the interpretation of the proposition in the scope of the evidential. In (8), Maria is not writing a book in the actual world. Yet the evidential construction is felicitous in such a context, because $p$ is true in the worlds compatible with what the speaker 
believes.

(8) Inferential context: After your aunt Maria died, Ivan found a first chapter of an unauthored manuscript in her apartment. He inferred that Maria was writing a book. You know that it was Maria's sister who was writing the book, not Maria. When someone asks Ivan what Maria was doing before she died, he says:

Maria pisala kniga.

Maria write.IMPERF.PAST.PLE book

'Maria was writing a book, [I inferred].'

As far as the strength of the speaker's commitment is concerned, I assume, following Izvorski (1997), that the evidential encodes a universal quantificational force. This assumption is supported by the fact that the evidential is infelicitous if the speaker views the proposition $p$ as a mere possibility (9).

(9) Inferential context: After your aunt Maria died, you found an unfinished manuscript in her apartment. It could be the case that Maria was writing a book, or it could be that the manuscript was written by Maria's sister. You are not sure. When someone asks you what Maria was doing before she died, you say:

\# Maria pisala kniga.

Maria write.IMPERF.PAST.PLE book

'Maria was writing a book, [I inferred].'

The modal analysis is further supported by the fact that the Bulgarian evidential patterns with modals with respect to the modal subordination phenomenon (cf. McCready and Ogata 2007 on Japanese evidentials). ${ }^{3}$ The example in (10a), adapted from Roberts 1989: 697, shows that the modal might blocks anaphoric reference between the pronominal subject he in the second sentence and its antecedent $a$ thief in the first sentence. The anaphoric dependence is possible only if the sentence with the pronominal subject contains a modal element, such as would in (10b).

(10) a. A thief ${ }_{i}$ might break into the house. $\# \mathrm{He}_{i}$ takes the silver.

b. A thief ${ }_{i}$ might break into the house. $\mathrm{He}_{i}$ would take the silver.

The examples in (11) show that the Bulgarian evidential patterns with modals as far as the modal subordination phenomenon is concerned: the evidential form izjal 'ate' in (11a) blocks anaphoric reference between the subject of the first

3 For the sake of space, I do not discuss other modal diagnostics here but see Smirnova 2011. 
The meaning of the Bulgarian evidential

sentence, Ivan, and the referential pronoun toj 'he' in the second sentence. If, however, the second sentence contains a modal, such as trjabva 'must' in (11b), the anaphoric dependency is reestablished.

(11) Inferential context: Last night there was a full tray of baklava in the fridge, but now it is gone. When you go to Ivan's room you notice baklava crumbs all over the place. You inferred that Ivan ate the baklava. When Maria asks you what happened to the baklava, you say:

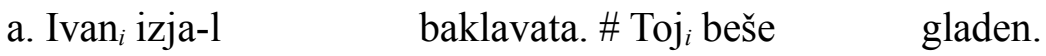

Ivan eat.PERF.PAST.PLE baklava. He be.3SG.PAST hungry.

'Ivan ate the baklava, [I inferred]. He was hungry.'

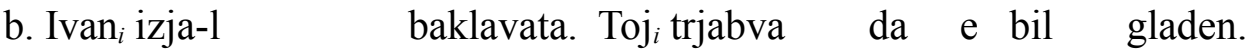

Ivan eat.PERF.PAST.PLE baklava. He must.PRES SUBJ be be.PLE hungry.

'Ivan ate the baklava, [I inferred]. He must have been hungry.'

The parallel between (10) and (11) provides further support for the modal analysis of the Bulgarian evidential.

Can the modal analysis of the evidential in inferential contexts outlined above be extended to account for the meaning of the evidential in reportative contexts? As discussed in section 1, one problem with the assumption that in reportative contexts the proposition $p$ in the scope of the evidential is interpreted with respect to the speaker's belief worlds is that in such contexts the speaker does not have to be committed to the truth of $p$. In (12), the speaker believes that $p$ is false, yet the evidential form is felicitous (see also 4).

(12) Reportative context: Ivan told you that before she died, Maria was writing a book. You know that it was Maria's sister who was writing the book, not Maria. When Ivan commends Maria for writing a book, you say:

Maria pisala kniga! Ta tja nito edin red

Maria write.IMPERF.PAST.PLE book EMPH she NOT one line

ne e napisala.

NOT be.3SG.PRES write.PERF.PAST.PLE

'Maria was writing a book, [I hear]! She hasn't written a single line.'

Faller (2002) argues that a felicitous assertion of the form $E V p$ followed by the denial of $p$, shown in (12) for Bulgarian, is an indication that the evidential construction does not have a modal component. This argument is based on the assumption that a modal statement cannot be used if the speaker knows for a fact whether $p$ is true or false.

Shall we assume that the Bulgarian evidential in reportative contexts does not 
have a modal component? This position is advocated by Sauerland and Schenner (2007) in their analysis of evidentiality in Bulgarian, shown in (13), where rep is the evidential operator in reportative contexts, and $p$ is a proposition in its scope.

(13) The interpretation of $\llbracket \operatorname{REP} \rrbracket(y, v)(p)$ (Sauerland and Schenner 2007: 532)

a. Presupposition: $y$ has in $v$ reportative evidence for $p$

b. Assertion: $p$

Since Sauerland and Schenner's analysis is non-modal, the proposition $p$ in the scope of the evidential is interpreted with respect to the actual world. Such an analysis predicts the evidential construction to be infelicitous if the state of affairs described by $p$ does not hold in the actual world. That such an analysis is not suitable for the Bulgarian evidential in reportative contexts is seen from the data in (4). In (4), Eli was not offered a job by aliens in the actual world, yet the evidential construction is felicitous in such a context.

I conclude that the data in (12) do not argue against a modal analysis of the evidential in reportative contexts (contra Faller 2002). What the pattern in (12) indicates is that the speaker's belief worlds are irrelevant for the interpretation of the proposition in reportative contexts. I argue that the modal analysis of the evidential in reportative contexts is still possible under the assumption that in such contexts the proposition in the scope of the evidential is interpreted with respect to the original reporter's belief worlds, not those of the speaker. Such an analysis of the evidential in reportative contexts is modeled after reports de dicto and constructions with reportative verbs such as say, shown in (14).

\section{Ivan believes/says that it is raining but it is not raining.}

The sentence in (14) is felicitous because the proposition $p$ (it is raining) is evaluated with respect to Ivan's belief worlds in the first conjunct, and with respect to the speaker's belief worlds in the second conjunct. ${ }^{4}$ I propose that the same explanation applies to the evidential construction in (12). The proposition that Maria is writing a book is interpreted with respect to the reporter's belief worlds, not those of the speaker. Thus, in a reportative context the speaker can felicitously follow up the assertion of the form EV $p$ with the denial of $p$. This analysis explains why the speakers can use the evidential to report information they believe to be false.

4 The data in (14) suggest that Faller's criterion, i.e. the infelicity when the embedded proposition is known to be false by the speaker, is only a sufficient, not a necessary condition for a modal analysis. Propositional operators believe and say are standardly analyzed as having a modal component (Ogihara 1996, Abusch 1997). Yet embedding a proposition under the verb of saying, and then denying it, does not render the construction infelicitous, as shown in (14). 
The meaning of the Bulgarian evidential

\begin{tabular}{llll}
\hline \hline Grammatical Component: & Evidential operator & Evidential Tense & Aspect \\
\hline \hline $\begin{array}{l}\text { Encodes temporal relation } \\
\text { between.... }\end{array}$ & ST and EAT & EAT and RT & RT and ET \\
\hline \hline
\end{tabular}

Table 2 Temporal relations in the evidential construction in Bulgarian.

In the next section, I discuss the temporal contribution of the evidential. This discussion provides the background needed to explain why the Bulgarian evidential cannot express inferences about the future.

\subsection{The temporal component of the evidential construction}

As the data in Table 1 have shown, the Bulgarian evidential has different forms for the present, past, and future. Moreover, the distribution of these forms depends on the temporal relations specified in the contexts. For example, only the past tense evidential pisala 'write' is felicitous in the context in (15).

(15) Reportative context: Last month Ivan told you that Maria, your former classmate, spent last year writing a book, and that the book has just been published. At the class reunion, when someone asks you what Maria was doing last year, you say:

Maria pisala / \# pišela kniga.

Maria write.IMPERF.PAST.PLE / \# write.IMPERF.PRES.PLE book

'Maria was writing a book, [I heard].'

Previous analyses of the Bulgarian evidential lack a temporal component (cf. Izvorski 1997) and, as a consequence, cannot explain the pattern in (15).

The temporal analysis I propose is couched within a neo-Reichenbachian framework (Klein 1994). The traditional temporal ontology, consisting of Speech Time (ST), Reference Time (RT) and Event Time (ET), is enriched with an additional temporal parameter: Evidence Acquisition Time (EAT). EAT, originally introduced in Lee 2011, is the time at which the speaker acquires the relevant evidence for the proposition $p$ in the scope of the evidential. In (15), for example, EAT is the time at which the speaker learns from Ivan that Maria wrote a book. I argue that relations between EAT, ST, RT and ET are specified by the evidential operator, evidential tense, and grammatical aspect, as shown in Table 2. 


\subsubsection{The temporal contribution of the evidential operator}

An emerging body of the literature has shown that most commonly evidential constructions encode a precedence relation between EAT and ST (Lee 2011, Smirnova 2011). This assumption is intuitively justified: in order to utter an evidential sentence, the speaker must acquire the relevant evidence first. It is infelicitous to use the evidential construction before the speaker has acquired the relevant evidence, i.e. when ST precedes EAT (EAT $<$ ST), as shown by (16). Neither the past evidential form zagubila 'lost' nor the future evidential form śtjala da zagubi 'will lose' in (16a) can express that the speaker will acquire reportative evidence in the future. In order to convey the intended meaning, a construction with the matrix clause reportative verb must be used instead (16b).

(16) Reportative context: You just finished watching the World Cup final, where the Netherlands lost to Spain 0 to 1 . A minute later, Maria, who is a big fan of the Netherlands team, calls you on the phone. Before picking up the phone, you say to your husband:
a. \# Holandija zagubila
/ štjala da zagubi.
Holland lose.PERF.PAST.PLE / FUT.PLE SUBJ lose.PERF.3SG.PRES
Intended: 'The Netherlands lost, [I will hear].'
b. Maria šte kaže, če Holandija zagubi.
Maria FUT say.IMPERF.3SG that Holland lose.PERF.3SG.PAST
'Maria will say that the Netherlands lost.'

In the rest of this paper, I assume that the evidential operator in Bulgarian encodes a precedence relation between EAT and ST $(\mathrm{EAT}<\mathrm{ST}) .^{5}$

\subsubsection{The meaning of the evidential tense}

In this section, I argue that evidential tense should be analyzed as relative.

A tense is relative if it is interpreted not with respect to ST but with respect to

5 There are special contexts in Bulgarian when EAT overlaps with ST, i.e. when the speaker acquires the relevant evidence as she speaks. Such a temporal configuration is always associated with an exclamative intonational contour, as in (i):

(i) Reportative context: You ran into your old classmate Ivan, who tells you that Maria, an old friend of yours, has a successful academic career. In fact, right now she is busy writing a book. Upon hearing this news, you exclaim:

Maria pišela kniga!

Maria write.IMPERF.PREs.PLE book

'Maria is writing a book, [I hear]!'

I exclude evidential constructions with exclamative intonation from the discussion in this paper, thus excluding situations in which EAT overlaps with ST. See Smirnova 2011 for the analysis. 
The meaning of the Bulgarian evidential

some other contextually relevant time. For example, tenses in complements of propositional attitude verbs and reportative verbs are relative: the time of interpretation is determined by the tense on the main verb (Ogihara 1996, Abusch 1997, Gennari 2003). Thus, in (17) the embedded future form would play is interpreted with respect to the time of saying, which is located in the past. Therefore, the relevant reference time at which the piano playing event takes place can precede or follow ST, as the distribution of temporal adverbials in (17) shows.

(17) Ivan said [that Maria would play the piano yesterday/tomorrow].

An alternative analysis, under which the future tense in the embedded clause is absolute, i.e. is interpreted with respect to ST, incorrectly predicts that the reference time, and, consequently, the event of piano playing can only be located in the future with respect to ST.

The distribution of future evidential forms, such as štjala da piše 'will write' in (18), suggests that the evidential tense has a relative interpretation. In (18), the relevant reference time (as well as the eventuality of book writing) is past with respect to ST. The usage of the future evidential form in (18) can only be explained if the speaker presents the eventuality of book writing as located at some reference time which is future relative to EAT.

(18) Reportative context: In the morning, Ivan told you that Maria will spend the afternoon writing a portion of her book. In the evening, when your friend asks you what Maria was doing in the afternoon, you say:

Maria štjala da piše kniga.

Maria FUT.PLE SUBJ write.IMPERF.3SG.PRES book.

Lit.: 'Maria will be writing a book, [I heard].'

Further support for the assumption that EAT, and not ST, serves as the time of interpretation for evidential tenses comes from the distribution of past and present evidential forms. In (19), the reference time coincides with EAT. Only the present stem evidential, pišela 'write', is felicitous in such a context. In (20), on the other hand, the relevant reference time (as well as the book writing event) is past with respect to EAT, and only the past stem form pisala 'wrote' is felicitous in such a context.

(19) Reportative context: Last month at the class reunion Ivan told you that Maria is busy writing a book. When your old school friend asks you what Maria was doing last month, you say:
Maria pišela
/ \# pisala
kniga.

Maria write.IMPERF.pREs.PLE/ \# write.IMPERF.PAST.PLE book 
'I heard that Maria was writing a book (at the time of the report).' Lit.: 'Maria is writing a book, [I heard].'

(20) Reportative context: Last month Ivan told you that Maria, your former classmate, spent last year writing a book, and that the book has just been published. At the class reunion, when someone asks you what Maria was doing last year, you say:

Maria pisala / \# pišela kniga.

Maria write.IMPERF.PAST.PLE / \# write.IMPERF.PREs.PLE book

'I heard that Maria had been writing a book.'

Lit.: 'Maria was writing a book, [I heard].'

In the next section, I show how the assumption that the evidential encodes a precedence relation between EAT and ST $($ EAT $<\mathrm{ST})$, and the assumption that the evidential tense is relative, make correct predictions about the temporal meaning of evidential sentences.

\subsubsection{Temporal relations in evidential sentences: a larger picture}

Consider the evidential sentence in (21). The future evidential form štjala $d a$ piše 'will write' can either express that the eventuality of book writing is located at some time which is future with respect to ST, or at some time which is past with respect to ST. This is shown by the contexts in (21a) and (21b), respectively.

Maria štjala da piše kniga.

Maria FUT.PLE SUBJ write.IMPERF.3SG.PRES book

'Maria will be writing a book, [I heard].'

a. Context 1 (ST $<$ ET): Ivan told you in the morning that Maria will spend the evening writing a portion of her book. In the afternoon, when someone asks you what Maria will be doing in the evening, you say (21).

b. Context $2(\mathrm{ET}<\mathrm{ST})$ : Ivan told you in the morning that Maria will spend the afternoon writing her book. In the evening, when someone asks you what Maria was doing in the afternoon, you say (21).

The temporal meaning of the evidential sentence in (21) is derived as follows. The evidential operator specifies that EAT precedes ST $($ EAT $<\mathrm{ST})$, as shown in $(22 \mathrm{a})$. With respect to the meaning of tense, I assume that it encodes a relation between RT and the time of evaluation (cf. Klein 1994). Since the evidential tense is relative, the future evidential form štjala da piše 'will write' locates RT in the future with respect to EAT (EAT < RT), as in $(22 b)$. Finally, as it is standardly 
The meaning of the Bulgarian evidential

assumed within the (neo-)Reichenbachian framework, the imperfective aspect on piše 'write' encodes that RT is a subset of ET (22c). From these relations, it follows that the eventuality of book writing can either precede or follow ST, as shown in (22d).

(22) a. Evidential operator: EAT $<$ ST

b. Future tense: EAT $<$ RT

c. Imperfective aspect: $\mathrm{RT} \subseteq \mathrm{ET}$

d. From (a)-(c): ST $<$ ET or ET $<$ ST

The analysis in (22) correctly predicts that the future evidential form štjala da piše 'will write' can refer to events which are future or past with respect to ST (cf. the two contexts in (21)).

The discussion in sections 3.1 and 3.2 provides the necessary background for the formal analysis of the evidential in Bulgarian, presented in section 3.3.

\subsection{Formal analysis of the Bulgarian evidential}

I propose that the evidential construction in Bulgarian has the truth conditions as in (23).

(23) For any model $M$, assignment function $g$, time $t$, and worlds $w, w^{\prime}$ $\llbracket \mathrm{EV} p \rrbracket^{\mathrm{M}, \mathrm{g}, \mathrm{t}, \mathrm{w}}(w)(t)$ is defined iff the speaker has concrete evidence for $p$, where concrete evidence subsumes reports from someone else or evidencebased inferences about $p$.

If defined, $\llbracket \mathrm{EV} p \rrbracket^{\mathrm{M}, \mathrm{g}, \mathrm{t}, \mathrm{w}}(w)(t)=1$ iff there exists a time $t^{\prime \prime}$, located before the evaluation time $t$ in $w$, such that the speaker acquires the concrete evidence for $p$ at $t^{\prime \prime}$ and for all world-time pairs $\left\langle w^{\prime}, t^{\prime}>\right.$ compatible with what the relevant epistemic agent, the speaker or the reporter, believes in $w$ at $t^{\prime \prime}, p$ is true in $w^{\prime}$ at $t^{\prime}$.

The semantics of the evidential operator is spelled out in (24).

$E V: \lambda Q \lambda w \lambda t \exists t^{\prime \prime}\left[\left(t^{\prime \prime}<t\right) \& \forall\left(w^{\prime}, t^{\prime}\right)\left[\left(w^{\prime}, t^{\prime}\right) \in M B_{D O X(\alpha)}\left(w, t^{\prime \prime}\right) \rightarrow Q\left(w^{\prime}\right)\left(t^{\prime}\right)\right]\right]$, where $t^{\prime \prime}$ is EAT; $t$ is the time of evaluation for the entire evidential sentence; $t^{\prime}$ is the structural equivalent of $t^{\prime \prime}$ in the belief worlds, i.e. the attitude holder's now), $\alpha=$ speaker in inferential contexts, $\alpha=$ reporter in reportative contexts.

According to the proposed meaning in (24), the evidential operator encodes that there is a time at which the speaker acquires the relevant evidence for the 
proposition she reports, i.e. EAT $\left(t^{\prime \prime}\right)$. The evidential specifies that the time of evidence acquisition precedes $t$, the time of evaluation of the entire evidential utterance, as coded by $\left(t^{\prime \prime}<t\right)$. In matrix clauses, $t$ is identified with ST. ${ }^{6}$

Similar to necessity modals, the evidential has universal quantificational force, thus asserting that the proposition in the scope of the evidential is true in all world-time pairs compatible with what the relevant epistemic agent believes in the actual world $w$ at the time $t^{\prime \prime}$. The time $t^{\prime}$ is the structural equivalent of the evidence acquisition time $\left(t^{\prime \prime}\right)$ in the belief worlds; it corresponds to the attitude holder's now (cf. von Stechow 1995, Ogihara 1996, Abusch 1997). Technically speaking, it is the attitude holder's now $\left(t^{\prime}\right)$, and not $t^{\prime \prime}$, i.e. the evidence acquisition time, that serves as the time of evaluation for the proposition in the scope of the evidential. Under this analysis, any evidential sentence has two evaluation times, the evaluation time for the proposition in the scope of the evidential operator, i.e. the attitude holder's now, and the evaluation time for the whole evidential utterance, which is ST in main clauses.

The definition in (24) guarantees that similarly to modals, the evidential is compatible with different modal bases, which are contextually determined. In inferential contexts, the proposition in the scope of the evidential is evaluated with respect to the doxastic modal base relativized to the speaker $\left(\mathrm{MB}_{D O X}\right.$ (speaker) $)$. In reportative contexts, the proposition is evaluated with respect to the doxastic modal base relativized to the original reporter $\left(\mathrm{MB}_{D O X \text { (reporter })}\right)$, whose statement the speaker repeats. The proposed definition allows for a uniform analysis of the Bulgarian evidential in both reportative and inferential contexts. ${ }^{7}$

In the next section, I show how the proposed analysis explains the inability of future evidential forms to express inferences about the future.

\section{Explaining why the evidential cannot express inferences about the future}

The example in (25) shows that the Bulgarian evidential cannot express inferences about the future (cf. also (7)).

(25) Inferential context: When you looked at the sky this afternoon, it was cloudy. You inferred that it would rain tonight. Your friend is planning a picnic in the evening, and asks you your opinion about the weather. At the time of the conversation, you still believe that it will rain tonight. You say:

\# Štjalo da vali dovečera.
FUT.PLE SUBJ rain.IMPERF.3SG.PRES tonight
Intended: 'It will rain tonight, [I inferred].'

6 If the evidential is embedded under a propositional attitude verb, the time of the evaluation $(t)$ would be identified with the event time of the matrix verb (cf. Ogihara 1996, Abusch 1997).

7 Due to space limitations, I do not present the compositional analysis here. See Smirnova 2011. 
The meaning of the Bulgarian evidential

Consider the meaning of the future evidential sentence in (25). According to the analysis proposed in the previous section, the proposition $p$ in the scope of the evidential is evaluated with respect to EAT/attitude holder's now, which is located in the past of ST. The future tense of the evidential specifies that $p$ will be realized at some future time with respect to its evaluation time. Moreover, in inferential contexts, the speaker considers $p$ to be necessarily true. Thus, by using (25), the speaker communicates that at some time in the past she held the belief that it would rain at some future time. The assertion that $p$ is necessarily true with respect to the speaker's past belief states, communicated by the future evidential sentence in (25), is weaker than the assertion that $p$ is true with respect to the speaker's current belief states. Thus, the evidential sentence in (25) violates the maxim of quantity: at the time of the conversation the speaker believes that $p$ will be realized at some future time, yet she asserts her commitment to $p$ with respect to some past time. The same effect is observed in the English example in (26), where the past tense on the verb believe shifts the evaluation time of the proposition $p$ (it will rain tonight) to the past (cf. Abusch 1997).

(26) Context: same as (25)

\# I believed it would rain tonight.

That epistemic contexts such as (25) are incompatible with constructions that enable epistemic agents to assess future events from a past perspective only, is seen from the contrast between (27a) and (27b).

Context: same as (25)

a. Trjabva- $\varnothing$ da vali dovečera. must-PRES SUBJ rain.IMPERF.3SG.PRES tonight. 'In all probability, it will rain tonight.'
b. \# Trjabva-še da vali dovečera. must-PAST SUBJ rain.IMPERF.3SG.PRES tonight. 'It was supposed to rain tonight.'

(27a) is a construction with the present tense epistemic modal trjabva 'must' Assuming with Condoravdi (2002) that tense on the modal specifies the time of evaluation for the proposition in its scope, the proposition in the scope of trjabva 'must' in (27a) is interpreted with respect to ST/the speaker's current belief states. Constructions with present tense epistemic modals such as (27a) are standardly used to express inferences about the future in Bulgarian. If, however, the tense on the modal and hence the evaluation time for the proposition in its scope is past, as in $(27 \mathrm{~b})$, the construction becomes infelicitous in contexts such as (25).

The contrast between (27a) and (27b) suggests that in epistemic contexts 
about the future, the speaker is required to reassess her earlier inference that $p$ and to evaluate $p$ with respect to $\mathrm{ST} /$ her current belief states. This requirement might be due to the fact that the possibility of an event happening changes as the time progresses. As Condoravdi 2002: 81 observes, "certain states of affairs are live options for the future at some time but cease to be live options for the future at a later time." Unlike epistemic modals, which change the evaluation time depending on the tense (cf. (27a) vs. (27b)), in evidential sentences such as the one in (25), the evaluation time is conventionally restricted to the past by virtue of the meaning of the evidential operator. Thus, the evidential can only express the speaker's commitment to $p$ with respect to some past time. This is what makes the future evidential construction infelicitous in inferential contexts.

Unlike inferential contexts, future evidential forms in reportative contexts are felicitous, as shown in (28).

(28) Reportative context: According to the weather forecast that you heard an hour ago, it is supposed to rain this evening. Your friend is planning a picnic in the evening, and when she asks you your opinion about the weather, you say:

Štjalo da vali dovečera.

FUT.PLE SUBJ rain.IMPERF.3SG.PRES tonight

'It will rain tonight, [I heard].'

According to the analysis proposed in the previous section, reportative contexts crucially differ from inferential ones in that the proposition in the scope of the evidential is interpreted with respect to the reporter's belief worlds. Thus, the evidential construction in reportative contexts does not communicate anything about the speaker's commitment at the time of the conversation. Therefore, the principle that rules out future evidential forms in inferential contexts, as discussed above, does not apply in reportative contexts.

\section{Previous analyses of evidentiality in Bulgarian}

\subsection{Izvorski's (1997) uniform analysis of the Bulgarian evidential}

One of the most interesting and influential aspects of Izvorski's analysis, presented in (3), is the assumption that evidentials should be anlayzed on a par with epistemic modals. While the assumption that the evidential has a modal component is essentially correct, there are some technical problems with Izvorski's analysis.

First, the assumption that the speaker is committed to the truth of the proposition $p$ incorrectly predicts that the speaker cannot use the evidential in reportative contexts if she believes that $p$ is false. Izvorski attempts to circumvent 
The meaning of the Bulgarian evidential

this problem by assuming that the ordering source imposes additional restrictions on the set of worlds provided by the modal base. She proposes that worlds in which the source of information is considered to be unreliable are eliminated. This assumption affects the modal force, allowing it to vary from universal (if no worlds are eliminated) to existential (if there is a difference between the original and the resultant set) (cf. also Faller's (2002) discussion of Izvorski). However, even this variability in the modal force, "between weak possibility to necessity" (Izvorski 1997), still commits the speaker to the belief that $p$ is at least possible. Reports of false beliefs can be easily explained under the assumption that in reportative contexts the proposition in the scope of the evidential is interpreted with respect to the original reporter's belief worlds, as I proposed in section 3.

The second problem for Izvorski's analysis is the lack of the temporal component. Thus, her analysis predicts that the distribution of evidential forms is not sensitive to the temporal relations specified in the contexts. Specifically, her analysis cannot explain the difference in the distribution between past and present tense evidential forms, shown in (19) and (20).

In conclusion, the analysis I propose retains the main insights of Izvorski's original proposal: it has a modal component and allows for a uniform analysis of the evidential operator in reportative and in inferential contexts. In addition, my analysis explains the temporal meaning of the evidential and accounts for reports of false beliefs.

\subsection{Koev's (2011) temporal analysis}

Koev (2011) recognizes that the Bulgarian evidential has a temporal component. Similarly to the analysis I presented here (see also Smirnova 2011), Koev employs the four temporal parameters, i.e. RT, ET, ST, and EAT, for the analysis of temporal relations in evidential sentences. ${ }^{8}$ However, our temporal analyses radically differ with respect to how the labor is allocated between different components of the evidential construction. First, Koev assumes that the evidential in reportative and inferential contexts encodes that RT precedes EAT (RT $<$ EAT). Second, in his analysis the evidential tense specifies the temporal location of RT with respect to ST. Thus, he assumes that evidential tense is absolute, not relative.

I find both assumptions to be problematic. First, as I argued above, the absolute tense analysis cannot be maintained for Bulgarian. Such an analysis cannot explain why future evidential forms can refer to eventualities that are past with respect to ST (cf. (18)), nor can it explain the difference in the distribution of past and present tense evidential forms in (19) and (20).

Second, the assumption that the evidential in reportative and inferential

8 Koev uses different terminology: EAT, RT, ET, and ST in my analysis correspond to his Learning Time (LRN), Topic Time (TT), ET, and Utterance Time (UT), respectively. 
contexts encodes a precedence relation between RT and EAT $(\mathrm{RT}<\mathrm{EAT})$ predicts that the evidential cannot be used if RT coincides with EAT $(\mathrm{RT}=\mathrm{EAT})$ or, for that reason, if RT is future with respect to EAT $(\mathrm{EAT}<\mathrm{RT})$. These temporal contexts are presented in (29) and (30), respectively. Contra to the predictions of Koev's analysis, the evidential form is felicitous in both contexts.

(29) Reportative context (RT = EAT): At the class reunion last month Ivan told you that Maria is busy writing a book. Two weeks later, when your old friend asks you what kept Maria from coming to the class reunion, you say:

Maria pišela kniga.

Maria write.IMPERF.PRES.PLE book

'Maria was writing a book, I heard.'

(30) Reportative context $(\mathrm{EAT}<\mathrm{RT})$ : In the morning Ivan told you that Maria will spend the evening writing a portion of her book. When in the afternoon your friend asks you what Maria will do in the evening, you say:

Maria štjala da piše kniga.

Maria FUT.PLE SUBJ write.IMPERF.3SG.PRES book

'Maria will be writing a book, [I heard].'

While Koev presents an interesting perspective on the meaning of the evidential in Bulgarian - his analysis also discusses the discourse status of information expressed by the evidential prejacent, a topic that I don't cover here his temporal analysis, and, specifically, the assumption that the evidential tense is absolute, as well as the assumption that the evidential in inferential and reportative contexts encodes that RT precedes EAT, cannot be maintained.

\section{Conclusions}

In this paper I have proposed a uniform analysis of the Bulgarian evidential in reportative and inferential contexts. I argued that the Bulgarian evidential has a temporal and an epistemic modal component. The modal component specifies that the proposition in the scope of the evidential is interpreted with respect to the doxastic modal base relativized to the speaker in inferential contexts and the doxastic modal base relativized to the reporter in reportative contexts. The temporal component encodes that there is a contextually salient time at which the speaker has acquired the relevant evidence for her evidential statement. This analysis has a wider empirical coverage than the previous analyses of evidentiality in Bulgarian (Izvorski 1997, Koev 2011). It explains why in reportative contexts the speakers can use the evidential to report false beliefs, and accounts for the inability of the Bulgarian evidential to express inferences about the future. 
The meaning of the Bulgarian evidential

\section{References}

Abusch, Dorit. 1997. Sequence of Tense and Temporal de re. Linguistics and Philosophy 20(1). 1-50. doi:10.1023/A:1005331423820

Aikhenvald, Alexandra. 2004. Evidentiality. Oxford: Oxford University Press.

Aksu-Koç, Ayhan \& Dan Slobin. 1986. A psychological account of the development and use of evidentials in Turkish. In Wallace Chafe \& Johanna Nichols (eds.), Evidentiality: The Linguistic Coding of Epistemology, 159-167. Norwood, NJ: Ablex.

Condoravdi, Cleo. 2002. Temporal interpretation of modals. In David Beaver, Stefan Kaufmann, Brady Clark \& Luis Casillas (eds.), The Construction of Meaning, 59-88. Stanford: CSLI Publications.

Faller, Martina. 2002. Semantics and Pragmatics of Evidentials in Cuzco Quechua. Palo Alto, CA: Stanford dissertation.

Friedman, Victor. 2005. Admirativity: Between modality and evidentiality. Sprachtypologie und Universalienforschung, 58 (1). 26-37.

Gennari, Silvia. 2003. Tense meaning and temporal interpretation. Journal of Semantics 20(1). 35-71. doi:10.1093/jos/20.1.35

Izvorski, Roumyana. 1997. The present perfect as an epistemic modal. In A. Lawson \& E. Cho (eds.), Semantics and Linguistic Theory (SALT) 8, 222-239. Cornell: CLC Publications.

Klein, Wolfgang. 1994. Time in Language. London: Routledge.

Koev, Todor. 2011. Evidentiality and temporal distance learning. Paper presented at SALT 21. Rutgers University.

Lee, Jungmee. 2011. The Korean evidential -te: A modal analysis. In O. Bonami \& P. Cabredo Hofherr (eds.), Empirical Issues in Syntax and Semantics 8, 287-311.

McCready, Eric \& Norry Ogata. 2007. Evidentiality, modality and probability. Linguistics and Philosophy, 30(2).147 - 206. doi:10.1007/s10988-007-9017-7

Newmark, Leonard, Philip Hubbard \& Peter Prifti. 1982. Standard Albanian. A reference Grammar for Students. Stanford, CA: Stanford University Press.

Ogihara, Toshiyuki. 1996. Tense, Attitude, and Scope. Dordrecht: Kluwer.

Reichenbach, Hans. 1947. Elements of Symbolic Logic. New York: Macmillan.

Roberts, Craige. 1989. Modal subordination and pronominal anaphora in discourse. Linguistics and Philosophy 12(6). 683-721. doi:10.1007/BF00632602

Sauerland, Uli \& Mathias Schenner. 2007. Shifting evidentials in Bulgarian. In Estela Puig-Waldmüller (ed.), Sinn und Bedeutung (SuB) 11, 525-539. Barcelona: Universitat Pompeu Fabra.

Smirnova, Anastasia. 2011. Evidentiality and Mood: Grammatical Expressions of Epistemic Modality in Bulgarian. Columbus, OH: The Ohio State University dissertation. 
Willett, Thomas. 1988. A cross-linguistic survey of the grammaticization of Evidentiality. Studies in Language 12(1). 51-97. doi:10.1075/s1.12.1.04wil

von Stechow, Arnim. 1995. Tense in Intensional Contexts: Two Semantic Accounts of Abusch's Theory of Tense. Ms, University of Tübingen.

\author{
Anastasia Smirnova \\ Tufts University \\ 111 Miner Hall \\ Medford, MA 02155 \\ Anastasia.Smirnova@tufts.edu
}

